\title{
Inhibitory Effect of Foeniculum Vulgare Leaf Extract on Alpha-glucosidase and Alpha-amylase Activity
}

\author{
Palukuri Yashwanth kumar ${ }^{1}$ and Mythily Subramaneyaan ${ }^{2 *}$ \\ ${ }^{1}$ Department of Medical Lab Technology, School of Medical and Allied Sciences, \\ Galgotias University, India \\ ${ }^{2}$ Division of Life Sciences, School of Basic and Applied Sciences, Galgotias \\ University, India \\ *Corresponding Author: Mythily Subramaneyaan, Division of Life Sciences, School \\ of Basic and Applied Sciences, Galgotias University, India.
}

Received: August 25, 2021

Published: December 06, 2021

(C) All rights are reserved by Palukuri

Yashwanth kumar and Mythily

Subramaneyaan.

\begin{abstract}
Diabetes mellitus is a chronic disease with a tremendous global incidence. Inhibition of carbohydrates digesting enzymes ( $\alpha$-amylase and $\alpha$-glucosidase) retards glucose absorption thereby attenuates hyperglycemia is one of many approaches used for the management of this disease. The present study is aimed to analyse the inhibitory effect of ethanolic extract of Foeniculum vulgare (FV) on $\alpha$-amylase and $\alpha$-glucosidase and its phytochemical screening. Phytochemical analysis of ethanol extract of Foeniculum vulgare showed major classes of secondary metabolites namely flavonoid, steroid, alkaloid, saponin, triterpenoid, quinone, tannins, coumarin, and phenol. The ethanolic extract of $F V$ exhibited inhibition of $\alpha$-amylase and $\alpha$-glucosidase by $87.14 \%$ in and $85.20 \%$ at $1000 \mu \mathrm{g} / \mathrm{ml}$, this might be due to phytochemicals/secondary metabolites. The results of the present study prove that the ethanolic extracts of $F V$ were effective in inhibiting $\alpha$-amylase and $\alpha$-glucosidase activity that might lead to the reduction of glucose levels. The results of this study suggest that the ethanolic extract of $F V$ might be potent antidiabetic.
\end{abstract}

Keywords: Foeniculum vulgare; Secondary Metabolites; Alpha Amylase; Alpha Glucosidase; Type 2 Diabetes Mellitus; Anti-diabetic Activity

\section{Abbreviations}

FV: Foeniculum vulgare; FVEE: Ethanolic Extract of Foeniculum vulgare; T2D: Type-2 Diabetes Mellitus

\section{Introduction}

Diabetes mellitus is a chronic metabolic disorder characterized by hyperglycaemia. According to an estimation of the International Diabetes Federation, approximately 366 million people are suffering from diabetes globally and around 41 million in India [1]. Regulation of blood glucose level is important for the onset of Type-
2-Diabetes (T2D). Inhibition of carbohydrates digesting enzymes ( $\alpha$-amylase and $\alpha$-glucosidase) retards glucose absorption thereby attenuates hyperglycemia is one of many approaches used for the management of this disease [2]. Alternatively, inhibitors carbohydrate digesting enzymes might control hyperglycaemia [3].

Insulin a pancreatic hormone regulates carbohydrate and fat metabolism in the body and storing of glycogen in hepatic, skeletal and adipose tissues. Low level of insulin or dysfunctional insulin will result in diabetes mellitus. Hence, insulin is the first line treatment for diabetes mellitus [4]. 
Alpha amylase hydrolyses dietary starch into glucose prior to absorption. Alpha-glucosidase, a membrane bound enzyme catalyses the cleavage of disaccharides to glucose. So, inhibitors carbohydrates digesting enzymes may reduce the absorption of dietary carbohydrates and suppress post-prandial hyperglycemia. Inhibition of alpha amylase and alpha glucosidase can lead to reduction in post prandial hyperglycemia in diabetic condition $[5,6]$ and they could be one of the most effective approaches to control diabetes. Currently available therapies for diabetes include insulin and various oral antidiabetic agents such as sulfonylureas, biguanides and glinides. Many of them have several serious adverse effects; therefore, the search for more effective and safer hypoglycemic agents is one of the important areas of investigation.

$\alpha$-amylase and $\alpha$-glucosidase inhibitors from plant sources offer an attractive strategy to attenuate hyperglycaemia due to their efficacy and less/nil side effects and a strong inhibition activity against $\alpha$-glucosidase [7]. Widespread species of plants have been described in literature for potential hypoglycemic activity. Due to their efficacy, less/nil side effects and relatively low costs, herbal drugs are used widely in developing countries even when their biologically active compounds are unknown $[8,9]$.

Today in this modern world, even though synthetic drugs are readily available and highly effective in curing various diseases, there are people who still prefer using traditional folk medicines because of their less harmful effects. There is a wide diversity of compounds, especially secondary metabolites, found and isolated from plants and studies have shown that these compounds have anticancer, antioxidant, anti-diabetic, antibacterial, analgesic, antiinflammatory, antitumor, antiviral and many other activities to a greater or lesser extent [10]. Many bioactive compounds from different plants have been reported to have hypoglycemic effect, in that mostly phenolics and triterpenoids such as oleanane, ursane, lupane, and flavonoids have a positive correlation as antidiabetic agents $[11,12]$.

There has been a lot of effort to identify and develop functional food and lead compounds that are suitable for the treatment of diabetes. Plant-based $\alpha$-amylase and $\alpha$-glucosidase inhibitors are phytoconstituents that have various pharmacological and physiological functions. Plant based drugs have been widely used for diabetic treatment over thousands of years due to their traditional acceptability, efficacy, and lesser side effects. With greater incidence, management of diabetes without any side effects is still a challenge $[12,14]$. Hence, screening of plant based $\alpha$-amylase and $\alpha$-glucosidase inhibitors had received much attention.

Foeniculum vulgare (FV), fennel is known to be used for its various medicinal properties. Numerous studies have shown its various pharmacological activities due to its phytoconstituents such as phenolic compounds, flavonoids, and fatty acids etc. [15-18]. Though various studies have been conducted on the different medicinal properties of FV, the present study was focused on assessing the effects of ethanolic extract of the plant on the anti-diabetic properties of FV by the phytochemical analysis, $\alpha$-amylase, and $\alpha$-glucosidase inhibitory activity.

\section{Materials and Methods}

Collection of plant material and preparation of crude extracts

The plant materials of Foeniculum vulgare were obtained from a market in Chennai, Tamil Nadu, India. The plant materials obtained were identified and authenticated. They were washed in tap water and then air dried at room temperature. Cold percolation method was used to obtain the ethanolic extract of FV [19]. The extract was prepared in 1:5 (w/v) at room temperature for 48 hours. The extract was filtered using a No. 1 Whatmann filter and processed in a vacuum evaporator.

Phytochemical screening of ethanol extract of foeniculum vulgare

Qualitative tests were performed to assess the nature of phytochemicals present in the ethanolic extract of Foeniculum vulgare (FVEE) as per the standard procedure [18].

\section{Liebermann-burchard test}

Extract was dissolved in minimum of chloroform. Acetic acid was added and heated. Few drops of acetic anhydride and concentrated $\mathrm{H}_{2} \mathrm{SO}_{4}$ were added. Green colour shows the presence of Steroid.

\section{Noller's test}

Extract was treated with tin and thionyl chloride and was heated in a water bath. Purple colour shows the presence of Triterpenoid. 
Shinoda test

Extract was dissolved in alcohol. Magnesium bits and concentrated hydrochloric acid was added. It was heated in a water bath. Majenta colour shows the presence of Flavonoid.

Test for furan

Extract was dissolved in alcohol. p-dimethyl amino benzaldehyde and concentrated hydrochloric acid was added and was heated in a water bath. Pink colour shows the presence of Furans.

Test for sugar

Extract was treated with anthrone and concentrated $\mathrm{H}_{2} \mathrm{SO}_{4}$. It was heated in a water bath. Green colour shows the presence of Sugar.

\section{Test for coumarin}

Extract was shaken with $10 \% \mathrm{NaOH}$. Yellow colour shows the presence of Coumarin. The substance regenerates when concentrated $\mathrm{H}_{2} \mathrm{SO}_{4}$ is added.

Test for quinone

Extract was treated with concentrated $\mathrm{H}_{2} \mathrm{SO}_{4}$ Red colour shows the presence of Quinone.

\section{Test for saponin}

Extract was shaken with water. Frothing shows the presence of Saponin.

\section{Test for tannin}

Extract was shaken with water and lead acetate solution was added. White precipitate shows the presence of Tannin.

\section{Test for acid}

Extract was treated with sodium bicarbonate solution. Effervescence shows the presence of Acid.

Test for phenol

Extract was dissolved in alcohol. Ferric chloride is added. Bluish colour shows the presence of Phenol.

Test for alkaloid

Extract was taken in acetic acid and few drops of freshly prepared Dragendorff's reagent are added. A brick red or orange pre- cipitate shows the presence of Alkaloids.

$\alpha$-amylase and $\alpha$-glucosidase inhibitory activity

$\alpha$-amylase and $\alpha$-glucosidase inhibitory activity of FVEE at concentrations - $125 \mu \mathrm{g} / \mathrm{ml}, 250 \mu \mathrm{g} / \mathrm{ml}, 500 \mu \mathrm{g} / \mathrm{ml}, 750 \mu \mathrm{g} / \mathrm{ml}$ and $1000 \mu / \mathrm{ml}$ was carried out according to the standard method with minor modification $[19,20]$. The reaction mixture containing phosphate buffer ( $100 \mathrm{mM}, \mathrm{pH}=6.8$ ), enzymes ( $\alpha$-amylase- $2 \mathrm{U} /$ $\mathrm{ml}, \alpha$-glucosidase $-1 \mathrm{U} / \mathrm{ml}$ ), and $20 \mu \mathrm{l}$ of varying concentrations of extract and fractions $(125 \mu \mathrm{g} / \mathrm{ml}, 250 \mu \mathrm{g} / \mathrm{ml}, 500 \mu \mathrm{g} / \mathrm{ml}, 750 \mu \mathrm{g} /$ $\mathrm{ml}$ and $1000 \mu / \mathrm{ml}$ ) was preincubated at $37^{\circ} \mathrm{C}$ for $20 \mathrm{~min}$. Then, the substrate was added (substrate for $\alpha$-amylase - $1 \%$ soluble starch in $100 \mathrm{mM}$ phosphate buffer $\mathrm{pH}$ 6.8; substrate for $\alpha$-glucosidase 4-Nitrophenyl- $\beta$ - $D$-glucopyranoside, $5 \mathrm{mM}$ ) and incubated further at $37^{\circ} \mathrm{C}$ for $30 \mathrm{~min}$. The absorbance of the resulting mixture was measured at $540 \mathrm{~nm}$ and $405 \mathrm{~nm}$ for $\alpha$-amylase and $\alpha$-glucosidase inhibitory activity respectively. The results were expressed as percentage inhibition, which was calculated using the formula,

Inhibitory activity $(\%)=(1-A s / A c) \times 100$ (As-Absorbance of Standard, Ac-Absorbance of Control)

\section{Statistical analysis}

All data are represented as Mean \pm SD. The comparisons between the groups were analyzed (ANOVA and Bonferroni Test) using SPSS. A P-value $<0.05$ were significant.

\section{Results and Discussion}

In the present investigation FVEE was screened for phytochemical analysis, $\alpha$-amylase, and $\alpha$-glucosidase inhibitory effects in vitro. Phytochemical screening of FVEE was found to contain various phytochemical constituents (shown in Table 1). FVEE possessed presence steroid, triterpenoid, coumarin, flavonoid, quinone, saponin, tannin, phenol, and alkaloid. Normally, phytochemicals are found to be present in parts of the plants such as roots, stems, leaves, flowers, fruits, or seeds [21]. Phytochemicals play a vital role in preventing disease and promoting health. Numerous studies had been carried out to identify and isolate the chemical components, to establish their efficacy and to understand the underlying mechanism of their action [22].

In the present study FVEE were evaluated for their inhibitory effect on $\alpha$-amylase and $\alpha$-glucosidase enzymes by in-vitro meth- 
od. FVEE at different concentrations- $125 \mu \mathrm{g} / \mathrm{ml}, 250 \mu \mathrm{g} / \mathrm{ml}, 500$ $\mu \mathrm{g} / \mathrm{ml}, 750 \mu \mathrm{g} / \mathrm{ml}$ and $1000 \mu / \mathrm{ml}$ exhibited $\alpha$-amylase (Table 2) and $\alpha$-glucosidase inhibitory activity (Table 3 ). Alpha amylase and alpha glucosidase inhibition activity of ethanolic extracts of Foeniculum vulgare were significantly different from the Acarbose, the standard reference drug $(\mathrm{P}<0.05)$.

The use of herbal drugs as complementary approaches in existing medications for the treatment of diabetes as many plants are known for hypoglycemic activity. Mainly two carbohydrate hydrolyzing enzymes are responsible for the development of postprandial hyperglycaemia. $\alpha$-amylase and $\alpha$-glucosidase catalyze the digestion of polysaccharides to disaccharides and catalyze the formation of monosaccharides. Hence, inhibitors of $\alpha$-amylase and $\alpha$-glucosidase are useful in the control of hyperglycemia as they delay carbohydrate digestion, which consequently reduce the postprandial plasma glucose level [23-25].

\begin{tabular}{|l|c|c|c|}
\hline S. No & Phytochemical tests & FVEE & Phytochemical Present \\
\hline 1 & $\begin{array}{c}\text { Liebermann-Burchad } \\
\text { test }\end{array}$ & + & Steroid \\
\hline 2 & Noller's test & + & Triterpenoid \\
\hline 3 & Shinoda test & + & Flavonoid \\
\hline 4 & Furan test & - & --- \\
\hline 5 & Coumarin test & - & --- \\
\hline 6 & Sugar test & - & --- \\
\hline 7 & Quinone test & + & Quinone \\
\hline 8 & Saponin test & - & --- \\
\hline 9 & Acid test & - & --- \\
\hline 10 & Tannin test & + & Tannin \\
\hline 11 & Phenol test & + & Phenol \\
\hline 12 & Alkaloid test & + & Alkaloid \\
\hline
\end{tabular}

Table 1: Phytochemical screening of ethanol extract of leaves of Foeniculum vulgare (FVEE).

The use of enzymes that are known to inhibit the $\alpha$-glucosidase and $\alpha$-amylase enzyme in the small intestine helps in the digestion of carbohydrate and lowers the postprandial glucose level in people with diabetes [26-29]. This study focused on the use of FVEE for the development of new drugs with lesser adverse effects. The study showed that FVEE can inhibit the activity of $\alpha$-amylase. This

\begin{tabular}{|l|c|c|c|}
\hline $\begin{array}{l}\text { Sl. } \\
\text { No }\end{array}$ & $\begin{array}{c}\text { Concentrations } \\
(\boldsymbol{\mu g} / \mathbf{m l})\end{array}$ & Acarbose \% & $\begin{array}{c}\text { Foeniculum vulgare } \\
\mathbf{\%}\end{array}$ \\
\hline 1 & FVEE $125 \mu \mathrm{g}$ & $38.15 \pm 0.13$ & $35.23 \pm 0.22$ \\
\hline 2 & FVEE $250 \mu \mathrm{g}$ & $56.24 \pm 0.20$ & $53.20 \pm 0.33$ \\
\hline 3 & FVEE $500 \mu \mathrm{g}$ & $70.13 \pm 0.30$ & $69.31 \pm 0.45$ \\
\hline 4 & FVEE $750 \mu \mathrm{g}$ & $81.19 \pm 0.42$ & $79.19 \pm 0.39$ \\
\hline 5 & FVEE $1000 \mu \mathrm{g}$ & $88.13 \pm 1.31$ & $87.14 \pm 1.30$ \\
\hline
\end{tabular}

Table 2: Alpha amylase inhibition activity of ethanolic extracts of Foeniculum vulgare (FVEE).

\begin{tabular}{|l|c|c|c|}
\hline $\begin{array}{l}\text { S. } \\
\text { No }\end{array}$ & $\begin{array}{c}\text { Concentrations } \\
\boldsymbol{\mu g} / \mathbf{m l}\end{array}$ & Acarbose \% & $\begin{array}{c}\text { Foeniculum vulgare } \\
\mathbf{\%}\end{array}$ \\
\hline 1 & FVEE $125 \mu \mathrm{g}$ & $42.21 \pm 0.53$ & $40.19 \pm 0.20$ \\
\hline 2 & FVEE $250 \mu \mathrm{g}$ & $53.14 \pm 0.35$ & $59.33 \pm 0.13$ \\
\hline 3 & FVEE $500 \mu \mathrm{g}$ & $74.22 \pm 0.19$ & $65.24 \pm 0.21$ \\
\hline 4 & FVEE $750 \mu \mathrm{g}$ & $82.24 \pm 0.59$ & $80.22 \pm 0.19$ \\
\hline 5 & FVEE $1000 \mu \mathrm{g}$ & $87.19 \pm 1.24$ & $85.20 \pm 1.33$ \\
\hline
\end{tabular}

Table 3: Alpha glucosidase inhibition activity of ethanolic extracts of Foeniculum vulgare (FvEE).

result agrees with previous reports which indicated that hypoglycaemic activity through either increased secretion of the insulin from pancrease or similar action to the insulin [30]. Annona squamosa, custard apple, exhibited antidiabetic activity by promoting insulin release from the pancreatic islets, increasing utilization of glucose in muscle, and inhibiting the glucose output from liver [31].

The FVEE exhibits strong inhibition towards the activity of the enzyme viz., $\alpha$-amylase and $\alpha$-glucosidase. Kwon., et al. [26] suggested that plants based $\alpha$-glucosidase enzymes to treat postprandial hyperglycemia. The active components of the extract can inhibit the activity of the enzymes by binding to a separate site. It has been hypothesized that the phytoconstituents in FV inhibit the $\alpha$-amylase and $\alpha$-glucosidase enzymes

by binding to the substrate and preventing the breakdown of disaccharides. The use of these compounds could provide a variety of beneficial effects and further structural elucidation and characterization methodologies must be carried out to identify the bioactive constituents. The phytochemical constituents of FV exhibited 
antidiabetic potential by inhibiting alpha amylase and alpha glucose and this might be due to synergistic effect. This study shows that the FV's antidiabetic effect could be due to inhibition of alpha amylase and alpha glucosidase by its phytoconstituents. However, further study is needed to isolate the active principles in this plant which is responsible for this activity.

\section{Conclusion}

Diabetes is one of the world's greatest health problems, affecting about 171 million people and most of these will be dominated by those suffering from type 2 diabetes. This increasing trend in type 2 diabetes mellitus has become a serious medical concern worldwide, which accounts for $9 \%$ of deaths that prompts every effort in exploring for new therapeutic agents to stem its progress. Although the drug treatment for type 2 diabetes mellitus has been improved to some extent during the last decade, drug resistance is still a big concern that needs to be dealt with effective approaches. One of the strategies to monitor blood glucose for type II diabetes mellitus is to either inhibit or reduce the production of glucose from the small intestine. In the present investigation ethanol extract of Foeniculum vulgare was screened for phytochemical analysis and $\alpha$-amylase and $\alpha$-glucosidase inhibitory effects were studied in vitro. $\alpha$-amylase and $\alpha$-glucosidase inhibitors interfere with the digestion of carbohydrates, achieving better glycemic control. Thus, natural products of great structural diversity are still a good source for searching for such inhibitors, thereby motivating to explore biologically active compounds from the highly diverse plants. In our study ethanol extract of Foeniculum vulgare inhibit the $\alpha$-amylase and $\alpha$-glucosidase might be due to the presence of several phytochemicals such as flavonoid, steroid, alkaloid, saponin, triterpenoid, quinone, tannins, coumarin, and phenol in it. Plants have been a good source of medicine for the treatment of various type of disease, still many plants and active compounds obtained from plants have not been well characterized. More investigations must be carried out to evaluate the exact mechanism of action of medicinal plants with antidiabetic activity.

\section{Conflict of Interest}

The authors declare no conflict of interest.

\section{Bibliography}

1. Mitra A., et al. "Mechanistic studies of lifestyle interventions in type 2 diabetes". World Journal of Diabetes 3 (2021): 201-207.
2. Tiwari AK and Rao JM. "Diabetes mellitus and multiple therapeutic approaches of phytochemicals: Present status and future prospects". Current Science 83 (2002): 30-38.

3. Ghadyale V., et al. "Effective control of postprandial glucose level through inhibition of intestinal alpha glucosidase by Cymbopogon martinii (Roxb.)". Evidence-Based Complementary and Alternative Medicine 2012 (2012): 372909.

4. Benedict S., et al. "Intranasal insulin enhances postprandial thermogenesis and lowers postprandial serum insulin levels in healthy men". Diabetes 60.1 (2010): 114-118.

5. Al-Zuhair A., et al. "Two potent competitive inhibitors discriminating alpha-glucosidase family I from family II". Carbohydrate Research 339 (2004): 1035-1040.

6. Kimura K., et al. "Two potent competitive inhibitors discriminating alpha-glucosidase family I from family II". Carbohydrate Research 339 (2004): 1035-1040.

7. Afonne OE., et al. "Some pharmacological properties of synclisia scabrida iii". Indian Journal of Pharmacology 32 (2000): 239-241.

8. Daisy R., et al. "A novel steroid from Elephantopus Scaber L. an Ethnomedicinal plant with antidiabetic activity". Journal of Phytomedicine 16 (2009): 252-257.

9. Shirwaikar K., et al. "Antidiabetic activity of alcoholic stem extract of Coscinium fenestratum in streptozotocin nicotinamide induced type 2 diabetic rats". Journal of Ethnophaacology 97 (2005): 369-374.

10. Miliauskas G., et al. "Screening of radical scavenging activity of some medicinal and aromatic plant extracts". Food chemistry 85.2 (2004): 231-237.

11. Sales PM., et al. " $\alpha$-amylase inhibitors: A review of raw material and isolated compounds from plant source". Journal of Pharmacy and Pharmaceutical Sciences 15 (2012): 141-183.

12. Tundis R., et al. "Natural products as alpha-amylase and alphaglucosidase inhibitors and their hypoglycaemic potential in the treatment of diabetes: An update". Mini-Reviews in Medicinal Chemistry 10 (2010): 315-331.

13. Geethalakshmi DVL., et al. "A-amylase inhibitory activity of Trianthema decandra L". International Journal of Biotechnology and Biochemistry 6.3 (2010): 369-376. 
14. Dewanjee AK., et al. "Antidiabetic activity of Diospyros peregrina fruit: Effect on hyperglycemia, hyperlipidemia and augmented oxidative stress in experimental type 2 diabetes". Food and Chemical Toxicology 47 (2009): 2679-2685.

15. Badgujar SB., et al. "Traditional uses, phytochemistry and pharmacology of Ficus carica: A review". Pharmaceutical biology 52.11 (2014): 1487-1503.

16. Kooti W., et al. "Therapeutic and pharmacological potential of Foeniculum vulgare Mill: a review". Journal of HerbMed Pharmacology 4.1 (2015): 1-9.

17. Rather MA., et al. "Foeniculum vulgare: A comprehensive review of its traditional use, phytochemistry, pharmacology, and safety". Arabian Journal of Chemistry 9 (2016): S1574-S1583.

18. Harborne AJ. "Phytochemical methods a guide to modern techniques of plant analysis". springer science and business media (1998).

19. Ademiluyi AO and Oboh G. "Soybean phenolic-rich extracts inhibit key-enzymes linked to type 2 diabetes (a-amylase and a-glucosidase) and hypertension (angiotensin I am converting enzyme) in-vitro". Experimental and Toxicologic Pathology 65 (2013): 305-309.

20. Shai LJ., et al. "Inhibitory effects of five medicinal plants on rat alpha-glucosidase: Comparison with their effects on yeast alpha-glucosidase". Journal of Medicinal Plants Research 5 (2011): 2863-2867.

21. Saxena M., et al. "Phytochemistry of medicinal plants". Journal of pharmacognosy and phytochemistry 1.6 (2013).

22. Tan BL., et al. "Antioxidant and oxidative stress: A mutual interplay in age-related diseases". Frontiers in pharmacology 9 (2018): 1162.

23. Hasani-Ranjbar S., et al. "A systematic review of Iranian medicinal plants useful in diabetes mellitus". Archives of Medical Science 4 (2008): 285-292.

24. Matsui T., et al. "Alpha-glucosidase inhibitory profile of catechins and theaflavins". Journal of Agricultural and Food Chemistry 55 (2007): 99-105.

25. Mishra SB., et al. "An analytical review of plants for anti-diabetic activity with their Phytoconstituents and mechanism of action". International Journal of Pharmaceutical Sciences and Research 1 (2010): 1647-1652.

26. Kwon E Apostolidis and K Shetty. "Evaluation of pepper (Capsicum annuum) for management of diabetes and hypertension". Journal of Food Biochemistry 31.3 (2007): 370-385.

27. Matsuda T., et al. "Antidiabetogenic constituents from several natural medicines". Pure and Applied Chemistry 74.7 (2002): 1301-1308.

28. Matsui IA., et al. "Anti-hyperglycemic potential of natural products". Mini-Reviews in Medicinal Chemistry 6.3 (2006): 349356.

29. Ogunwande T., et al. " $\alpha$-Glucosidase inhibitory profile of Nigerian medicinal plants in immobilized assay system". Food Science and Technology Research 13.2 (2007): 169-172.

30. Bnouham M., et al. "Medicinal plants with potential antidiabetic activity-a review of ten years of herbal medicine research (1990-2000)". International Journal of Diabetes and Metabolism 14 (2016): 1-25.

31. Malviya N., et al. "Antidiabetic potential of medicinal plants". Acta Poloniae Pharmaceutica 67.2 (2010): 113-118.

\section{Assets from publication with us}

- Prompt Acknowledgement after receiving the article

- Thorough Double blinded peer review

- Rapid Publication

- Issue of Publication Certificate

- High visibility of your Published work

Website: www.actascientific.com/

Submit Article: www.actascientific.com/submission.php

Email us: editor@actascientific.com

Contact us: +919182824667 